551.508 .9

\title{
Meteorograph Designed for the Floating Balloon Experiment in Cosmic-Ray Research
}

\author{
by \\ K. Maeda and I. Yamaji \\ Meteorological Research Institute \\ (Received May 19, 1955)
}

The exposure of nuclear emulsions in the extreme upper atmosphere by making use of the floating balloons is one of the most fruitful experiments in cosmic. ray physics today.

In this kind of experiment, high accuracy is demanded for the recording of barometric pressure change during the flight, though the recording of temperature and humidity are not so important.

Moreover, these experiments become in vain unless the packages of nuclear emulsions that ascend with balloons are retrieved after the balloon-burst or their landing.

Considering such a situation, we designed simplified meteorographs for these experiments. The points devised are as follows.

By increasing the number of capsules* of the aneroid barograph, we can increase its barometric sensitivity but not its accuracy, because it also increases the amplitude of the irregular oscillations of itself

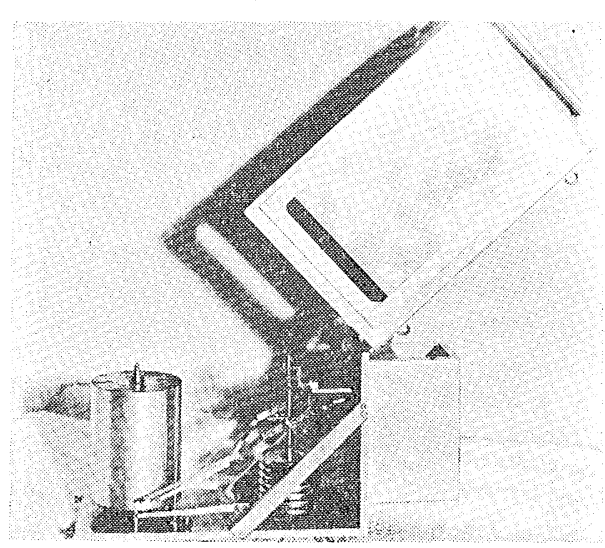

Fig. 1 General view of the meteorograph using the sliding-rod in the moving end of the aneroid barograph. during the flight and this brings the broadening of the described figures on the recording sheet.

Therefore, firstly we put the sliding-rod to the moving end of the capsule stack which is supported by the two fixed arms as can be seen from Fig. 1.

The use of the sliding-rod and its supporter diminishes the transversal oscillations of the capsule stack but it is found that this kind of supporting is unstable against the external shocks of the vertical direction because of the unbalance of the recording needle and its suspension by a string. Moreover, as one can see from the figure, the height of the metorograph is larger than usual (exceeding $140 \mathrm{~mm}$ ) and this goes counter to the demand for the compactness of this intruments.

In the next place, to improve in these respects, we used the counter-balance instead of the fixed supporter for the capsule stack and, moreover, the double-rod-

* The capsule is a tinny vacuum chamber made of phosphor-bronze foil. Its dimameter is $45 \mathrm{~mm}$ and the thickness is $5 \mathrm{~mm}$, see Figs. 1 and 2 . 
mechanism is utilized as an enlarging lever between the recording needle and the moving end of capsule stack as shown in Fig. 2.

The merits of the double-rod-mechanism is not only to prevent the oscillations of the recording needle but also to get larger barometric sensitivity in the upper atmosphere than in the lower air because the stroke of the jointing point of the second rod to the recording needle increases with the expansion of capsule stack as it approaches to the centre line.

In this way, the influence of the irregular motions during the flight on the recorder is eliminated but not so with regards to that of the temperature changes, as it is impossible to get on aneroid baro-

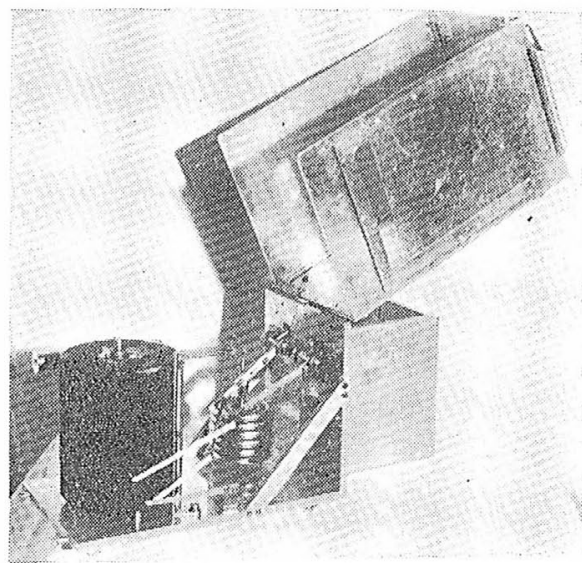

Fig. 2 General view of the meteorograph equipped with the counter-balance and the double-rod-mechanism. graph which does not suffer any thermal influences, at present. For the sake of the temperature correction for the bargraph, the variation of temperature is recorded by means of the bi-metal therometer. For their calibrations, an airtight chamber is prepared in which the pressure and the temperature can be changed simultaneously.

The records are drawn by the sharp needles which scratch the carbon-smoked aluminum sheet stuck on the surface of the metal cylinder which is driven by clock-work.

Previously, the clock-work of the recorder was a defect in the meteorograph because of the interruption of its motion before the run-down of its power

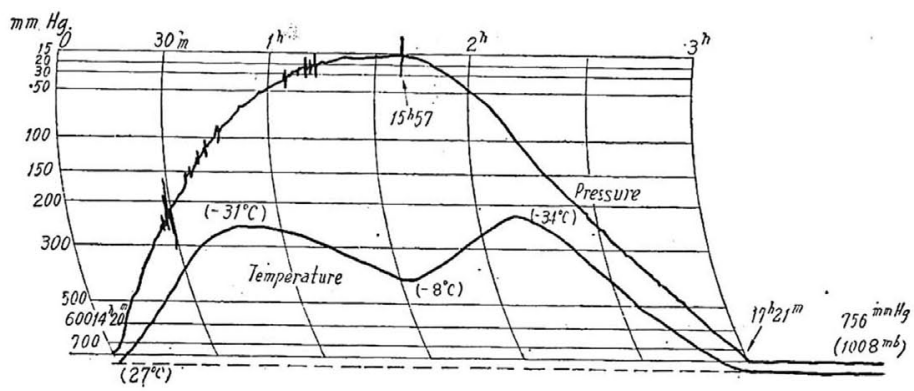

Fig. 3 The record of the meteorograph launched from the Aerological Observatory, Tateno, on Aug. 12. 1953. spring owing to the cooling in the upper atmosphere. But this trouble is solved by the use of silicon-oil (D. 121) as a lubricant. Although, the hygrometer is omitted, the total weight of this instrument is nearly over one kilogram, but this is reducible if one use cast aluminum for the frame instead of thick plates.

As examples of the results obtained by this type of meteorograph, the recorded sheets are shown in Figs. 3 and 4.

The former is the record of the floating balloon experiment in which four rubber balloons are used together. It was launched from the Aerological Observatory, Tateno, $14 \mathrm{~h} 22 \mathrm{~m}$ on August 12, 1953 and landed on a cartain village in Saitama prefecture, nearly $60 \mathrm{~km}$ south-west from Tateno after 3 hours flight. The maximum height was $27.5 \mathrm{~km}(20.2 \mathrm{mb})$. 
The details of these experiments are published in the report from the Central Meteorological Observatory [1].

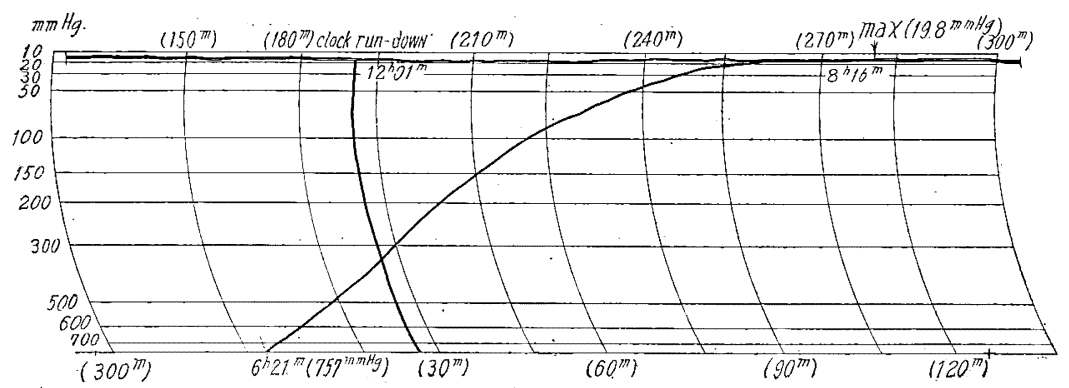

Fig. 4 The record of the meteorograph of launched from the Kobe University on Sep. 16, 1954.

The latter (Fig. 4) is the record of the first successful flight of the large polyethylen balloon in our country which was launched from the Kobe University at $6 \mathrm{~h} 22 \mathrm{~m}$ September 16, 1954, and fell on the Japan Sea off Shimane prefecture, about $80 \mathrm{~km}$ north-west from Kobe, after five hours floating above $15 \mathrm{mb}$ level. In this flight, the meteorograph was suspended in a gondola together with the emulsion packages and this gondola was enclosed in a thin polyethlen sheet. The wrapping sheet served also as a protector of the recorder from the water for several hours after its fall on the sea.

From this figure, it is noted that the disturbances during the flight were exceedingly small as compared with these of the flight by multiple rubber-balloons.

Acknowledgement_- The designs and the trial constructions of these instruments are indebted to Mr. S. TAMURA to whom we wish to express our cordial thanks.

The fund was partly supplied by the Scientific Research Expenditure of the Ministry of Education.

\section{Reference}

[1] Ishit, C., Maeda, K. and Minarawa, O., 1954: Report on the Floating Balloon Experiments for Cosmic-Ray Measurements, Journ. Met. Res. 6, p. 405. 